\title{
Circulating Tumor Cells as a Potential Biomarker in Selecting Patients for Pulmonary Metastasectomy from Colorectal Cancer: Report of a Case
}
M. Hashimoto ${ }^{a}$
F. Tanaka ${ }^{c}$
K. Yoneda ${ }^{a}$
N. Kondo ${ }^{a}$
T. Takuwa ${ }^{a}$
S. Matsumoto ${ }^{a}$
A. Kuroda ${ }^{a}$
M. Nodab
N. Tomita ${ }^{\text {b }}$
S. Hasegawa ${ }^{a}$

Departments of ${ }^{a}$ Thoracic Surgery and ${ }^{b}$ Surgery, Hyogo College of Medicine, Nishinomiya, and ' Second Department of Surgery (Chest Surgery), University of Occupational and Environmental Health, Kitakyushu, Japan

\section{Key Words}

Circulating tumor cells · Colorectal cancer - Pulmonary metastasectomy

\section{Abstract}

Pulmonary metastasectomy is indicated for selected patients with metastatic colorectal cancer. A 43-year-old woman presented with solitary pulmonary metastasis from descending colon cancer and pulmonary metastasectomy was performed because of absence of any other active metastasis as well as normal serum carcinoembryonic antigen value. However, she died due to early development of nodal and bone metastases within 6 months after thoracotomy. The presence of circulating tumor cells (CTCS) in the peripheral blood (6 CTCs $/ 7.5 \mathrm{ml}$ ) was the only factor to predict such a poor prognosis, suggesting that the CTC test is useful in selecting patients for pulmonary metastasectomy.

\section{Introduction}

Surgery for pulmonary metastases from colorectal cancer (CRC) is indicated for selected patients who meet conventional criteria as follows: (1) the metastases seem to be technically resectable; (2) the general and functional risks are tolerable; (3) the primary tumor is controlled; (4) no active extrathoracic lesions are detected [1, 2]. 
However, the optimal criteria to identify patients for whom pulmonary metastasectomy may provide a modest survival benefit remain controversial, although a number of studies have revealed potential prognostic factors such as serum carcinoembryonic antigen (CEA) level [3, 4]. Circulating tumor cells (CTCs) are potential surrogates of distant metastasis, and their presence is a novel and promising biomarker in the diagnosis and therapy of a variety of malignant tumors [5-8]. The CTC test using the CellSearch system (Velidex, LLC, North Raritan, N.J., USA), an automated quantitative CTC detection system, has been approved for monitoring of blood from metastatic CRC patients by the Food and Drug Administration in the USA. Here, we present the case of a woman with solitary pulmonary metastasis from CRC who died of tumor recurrence within 6 months after thoracotomy; the presence of CTCs in the peripheral blood sampled before thoracotomy was the only factor to predict such a poor prognosis.

\section{Case Report}

A 43-year-old Japanese woman with suspicion of a solitary pulmonary metastasis presented in September 2009, after a series of therapies for colon cancer as follows: (1) descending hemicolectomy (mucinous adenocarcinoma; stage IIIB: pSE and pN2H0M0) in November 2007; (2) adjuvant chemotherapy for 4 months: UFT (uracil/tegafur)/LV (leucovorin); (3) hepatectomy for liver metastasis in January 2009 and radiotherapy for left 8th rib metastasis in February 2009, and systemic chemotherapy for 4 months: FOLFOX (oxaliplatin/5-fluorouracil/leucovorin) + bevacizumab. A PET-CT scan revealed a solitary pulmonary nodule in the right lower lobe with suspicion of pulmonary metastasis, and no other active tumors in July 2009 (fig. 1a, b). Serum CEA level was normal $(2.2 \mathrm{ng} / \mathrm{ml})$, and pulmonary metastasectomy was performed with the establishment of pathological diagnosis of pulmonary metastasis. A 7.5-ml sample of peripheral blood taken just before thoracotomy was used for the CTC test, which revealed the presence of CTCs (6 CTCs/7.5 ml). Multiple nodal and bone metastases were found 1 month after thoracotomy (fig. $2 \mathrm{a}$ ), and developed (fig. 2b) in spite of received systemic chemotherapy. Finally, the patient died of tumor progression 172 days after thoracotomy.

\section{Discussion}

The present case showed a very poor prognosis of only 6 months' survival after pulmonary metastasectomy due to early development of nodal and bone metastases, although the case met the traditional selection criteria for pulmonary metastasectomy $[1,2]$. In addition, the present case had a normal serum CEA level, solitary pulmonary metastasis and no intrathoracic nodal metastasis, which are favorable prognostic factors revealed in previous studies [9-11]. Thus, the only factor to predict a poor prognosis in the case was her elevated CTC count (6 CTCs/7.5 ml peripheral blood), which was consistent with a study showing that an elevated CTC count ( 3 or more CTCs $/ 7.5 \mathrm{ml}$ ) was an independent and significant prognostic factor for shorter survival [7]. Thus, the present case suggests that patients with an elevated CTC count may not be good candidates for pulmonary metastasectomy even when the case meets the conventional selection criteria. A prospective study, to assess the clinical value of the CTC test in selecting patients for pulmonary metastasectomy, is warranted. 


\section{Acknowledgements}

This work was supported by JSPS KAKENHI grant No. 22791326 and Grant-in-Aid for Graduate Students, Hyogo College of Medicine. We thank Mayo Yamamoto for helpful assistance in preparation of the manuscript.

\section{Disclosure Statement}

The authors declare that they do not have anything to disclose regarding conflict of interest with respect to this work.
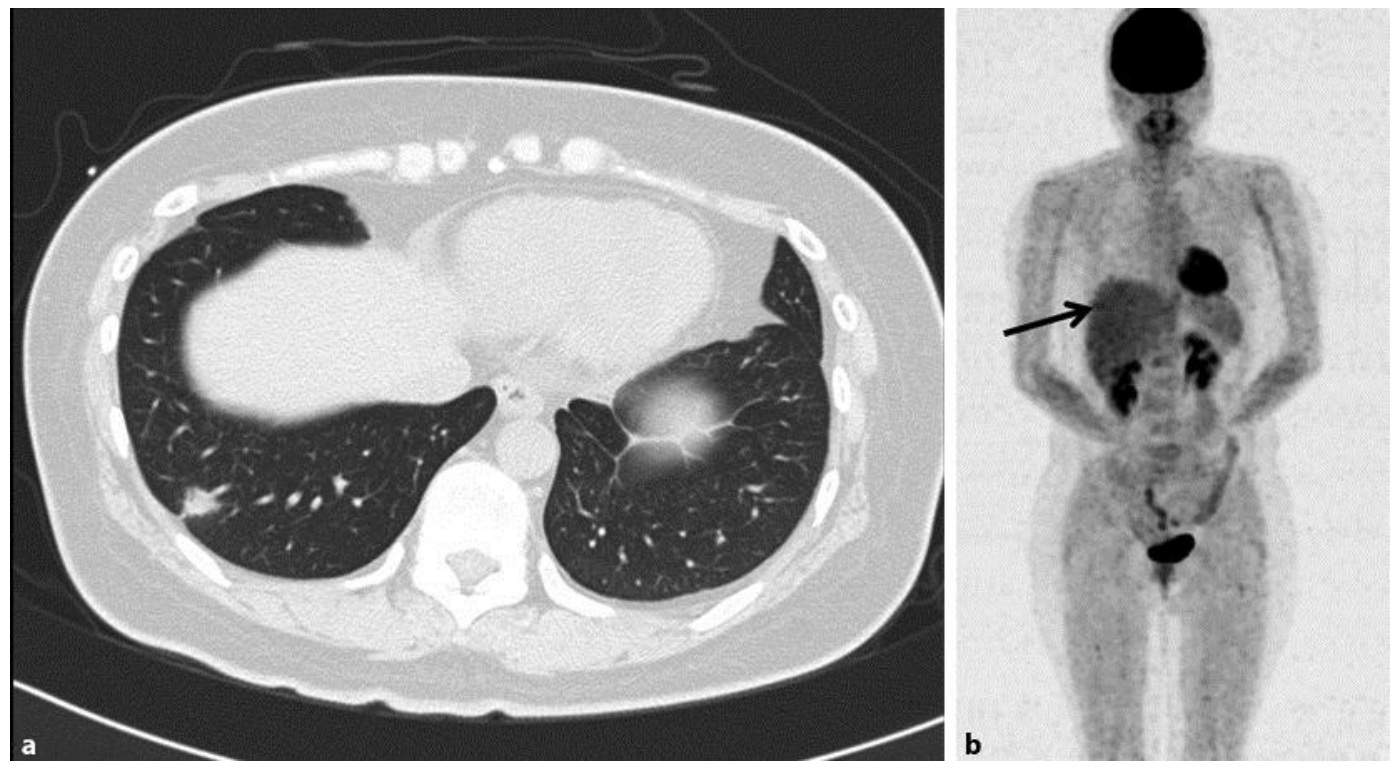

Fig. 1. PET-CT scan revealed a solitary pulmonary nodule in the right lower lobe with suspicion of pulmonary metastasis (a) and no other active tumors (b). 


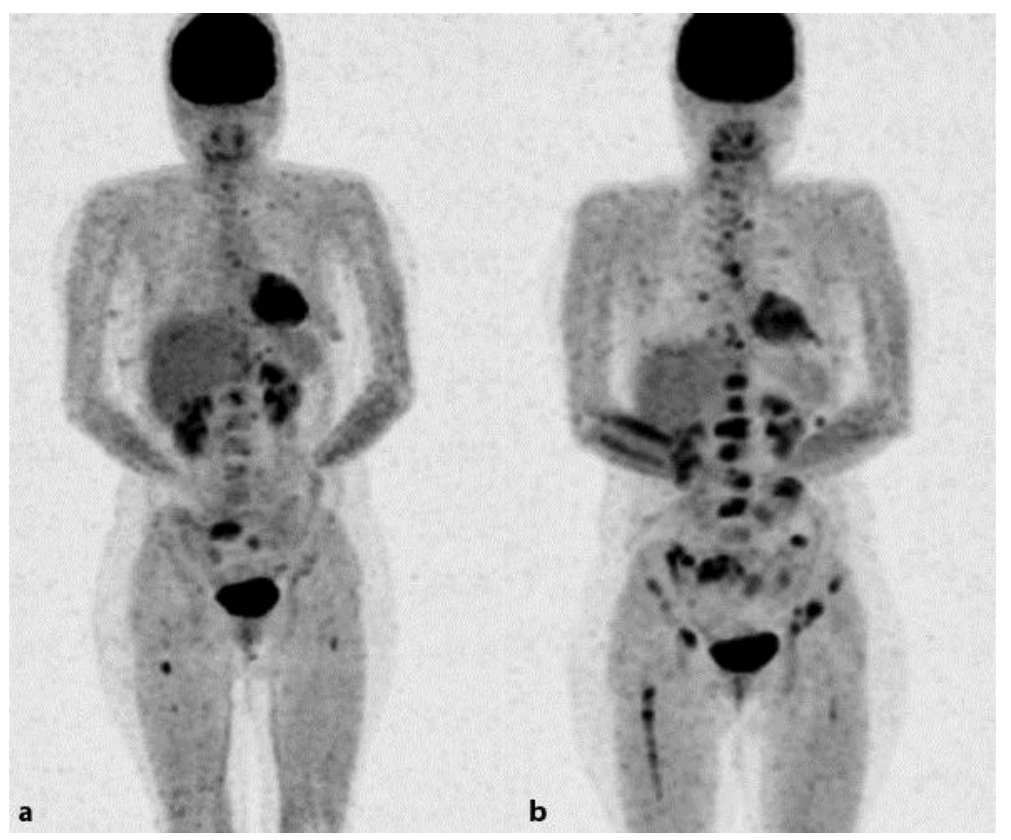

Fig. 2. Multiple nodal and bone metastases were found by PET-CT scan taken 1 month after thoracotomy (a), and they aggressively developed 4 months after thoracotomy (b).

\section{References}

1 Thomford NR, Woolner LB, Clagett T: The surgical treatment of metastatic tumors in the lung. J Thorac Cardiovasc Surg 1965;49:357-363.

-2 Watanabe T, Itabashi M, Shimada Y, Tanaka S, Ito Y, Ajioka Y, Hamaguchi T, Hyodo I, Igarashi M, Ishida H, Ishiguro M, Kanemitsu Y, Kokudo N, Muro K, Ochiai A, Oguchi M, Ohkura Y, Saito Y, Sakai Y, Ueno H, Yoshino T, Fujimori T, Koinuma N, Morita T, Nishimura G, Sakata Y, Takahashi K, Takiuchi H, Tsuruta O, Yamaguchi T, Yoshida M, Yamaguchi N, Kotake K, Sugihara K; Japanese Society for Cancer of the Colon and Rectum: Japanese Society for Cancer of the Colon and Rectum (JSCCR) guidelines 2010 for the treatment of colorectal cancer. Int J Clin Oncol 2012;17:1-29.

-3 Pfannschmidt J, Dienemann H, Hoffmann H: Surgical resection of pulmonary metastases from colorectal cancer: a systematic review of published series. Ann Thorac Surg 2007;84:324-338.

4 Treasure T: Pulmonary metastasectomy for colorectal cancer: weak evidence and no randomised trials. Eur J Cardiothorac Surg 2008;33:300-302.

5 Pantel K, Brakenhoff RH: Dissecting the metastatic cascade. Nat Rev Cancer 2004;4:448-456.

6 Ring A, Smithe IE, Dowsett M: Circulating tumour cells in breast cancer. Lancet Oncol 2004;5:79-88.

7 Cohen SJ, Punt CJ, Iannotti N, Saidman BH, Sabbath KD, Gabrail NY, Picus J, Morse M, Mitchell E, Miller MC, Doyle GV, Tissing H, Terstappen LW, Meropol NJ: Relationship of circulating tumor cells to tumor response, progression-free survival, and overall survival in patients with metastatic colorectal cancer. J Clin Oncol 2008;26:3213-3221.

-8 Tanaka F, Yoneda K, Kondo N, Hashimoto M, Takuwa T, Matsumoto S, Okumura Y, Rahman S, Tsubota N, Tsujimura T, Kuribayashi K, Fukuoka K, Nakano T, Hasegawa S: Circulating tumor cell as a diagnostic marker in primary lung cancer. Clin Cancer Res 2009;15:6980-6986.

-9 Okumura S, Kondo H, Tsuboi M, Nakayama H, Asamura H, Tsuchiya R, Naruke T: Pulmonary resection for metastatic colorectal cancer: experiences with 159 patients. J Thorac Cardiovasc Surg 1996;112:867874.

10 Higashiyama M, Kodama K, Higaki N, Takami K, Murata K, Kameyama M, Yokouchi H: Surgery for pulmonary metastases from colorectal cancer: the importance of prethoracotomy serum carcinoembryonic antigen as an indicator of prognosis. Jpn J Thorac Cardiovasc Surg 2003;51:289-296.

11 Saito Y, Omiya H, Kohno K, Kobayashi T, Itoi K, Teramachi M, Sasaki M, Suzuki H, Takao H, Nakade M: Pulmonary metastasectomy for 165 patients with colorectal carcinoma: a prognostic assessment. J Thorac Cardiovasc Surg 2002;124:1007-1013. 